\title{
Antidepressant and Stabilizing Effects of Thyroid Hormone Augmentation in Women's Mood Disorders
}

\author{
Barbara L Parry*, and Daniel F Kripke \\ Department of Psychiatry, University of California, USA \\ Submission: February 11, 2020; Published: March 11, 2020 \\ *Corresponding author: Barbara L Parry, Professor of Psychiatry, University of California, San Diego, USA
}

\begin{abstract}
Women are at increased risk for new onsets and recurrences of depressive illness that may occur at puberty, with oral contraceptive use, premenstrual, peripartum and at the perimenopause. Women also may develop thyroid disease during these times of reproductive hormonal change. For patients who develop mood disorders, most studies indicate that thyroid augmentation has the potential to enhance the response to antidepressant medication and to stabilize the mood disorder, particularly in women. Herein, we review the history of using thyroid supplements to enhance antidepressant responses, propose potential mechanisms, and provide selected case reports and prescription guidelines. In sum, thyroid augmentation strategies provide a high likelihood of significant clinical benefit, with relatively minor risks: For treatment-resistant depression, triiodothyronine (T3) (25-50 ug) tends to enhance antidepressant effects more than levothyroxine (T4), works best as an adjunctive agent rather than as monotherapy, is more efficacious in women than in men, and the antidepressant benefits may be observed in the context of euthyroid status. In women prone to rapid-cycling mood disorders, T4 has been shown to stabilize the potentially devastating rapid cycles of mood that occur in this severe form of bipolar illness. The aim of this report is to increase clinician awareness of these treatment strategies to enhance the well-being of women during their lifecycle, as untreated depressions may impair the optimal functioning and quality of life of the woman, deterring her ability to make valuable contributions to her family and society, and potentially leading to increased frequency, severity and more treatment-resistant depressive episodes.
\end{abstract}

\section{Introduction}

Women are at twice the risk to develop major depression compared with men [1]. Women also are more prone to thyroid impairment, although they are more responsive to thyroid treatment. Overt hypothyroidism is eight times more common in women than in men and increases with age. Women are at increased risk to develop thyroid impairment during times of reproductive hormonal change at puberty [2], postpartum and the menopausal transition, times at which they also are at increased risk to develop mood disorders. The reproductive-cycle transitions are a time of increased vulnerability for the development of rapidcycling bipolar illness, a severe mood disorder for which female sex, hypothyroidism and drug-induced triggering (also more prevalent in women) are risk factors. Women, more than men with treatment-resistant depression, however, tend to be more responsive to supplementation with liothyronine (T3), and women with rapid-cycling bipolar illness are more responsive than men to hypermetabolic doses of thyroxine (T4). Although the psychiatric literature is replete with studies and reviews about thyroid supplementation in the treatment of mood disorders, we think thyroid supplementation is used much less often than it should be. In our review of over 200 abstracts and articles describing the various drugs used for treating depression, mention of T3 or T4 usage is rare. Based on our review of the literature and experience interacting clinically and at professional conferences with primary care and other physicians, we think this area of women's health warrants further emphasis. This report aims to increase awareness of the potential for thyroid hormone augmentation to enhance responses to antidepressant and mood-stabilizing medications. We review the literature, delineate possible mechanisms, provide relevant case reports, and present treatment guidelines.

\section{Studies of Thyroid Treatment in Mood Disorders}

\section{Major Depression (Unipolar)}

Although $6.4 \%$ of psychiatrically depressed patients exhibit a low T3 syndrome (despite normal T4 and TSH levels) on admission, and hospital length of stay in male patients with depression is 
inversely related to the free $\mathrm{T} 4$ index, the antidepressant response of thyroid augmentation strategies is not predicted well by blood thyroid function tests $[3,4]$. A good response often occurs despite euthyroid status indicated by blood tests, T3 is more efficacious than T4 as an augmenting antidepressant in treatment-resistant depression, and an antidepressant response occurs more frequently in women [5].

T3 Treatment, Gender and Thyroid Function (e.g., Case A below): Initial studies provided some preliminary suggestion of T3 as a single therapeutic agent with antidepressant efficacy [6-8]. More efficacy has been found in subsequent studies using T3 as an augmenting agent or to accelerate antidepressant response. Prange et al. [9] reported triiodothyronine (T3) 25 ug or intramuscular injection of Thyroid Stimulating Hormone (TSH) 10 IU enhanced the antidepressant effects of imipramine, accelerating the response time in women, but not in men [10]. Men responded to initial doses of imipramine in a shorter period than women. Women treated with imipramine and thyroid supplement responded as rapidly as men treated with imipramine alone. In contrast, Goodwin et al. [11] later demonstrated that among tricyclic antidepressant non responders, men benefited from the addition of T3 as often as women. Coppen et al. [12] found that 30 unipolar or bipolar depressed euthyroid inpatients, when given T3 25 ug for the first two weeks of a four-week treatment trial with imipramine (150 mg daily) or L-tryptophan ( 9 grams daily), had a better response and less side effects than when imipramine was given alone. Although T3 augmentation worked equally well in men and women, it accelerated the response in women. (T3 did not enhance the therapeutic response to L-tryptophan alone.) In an algorithm-based treatment of major depression in an outpatient clinic, Agid and Lerer [13] found that adding T3 augmentation was more efficacious than increasing the dose of an SSRI (i.e., fluoxetine from 20 to $40 \mathrm{mg}$ ), and that $62.5 \%$ of the female patients and none of the males responded to 25-50 ug of T3. Tsutsui et al. [14] found in 11 patients with protracted depression that all but one (male) patient responded with improved mood with the addition of T3 (5-25 ug/day) to imipramine, clomipramine, amitriptyline or nortriptyline in 14-56 days (average 33.7 days). Although baseline levels of T3 and T4 were normal, TSH response to TRH was diminished, but normalized after T3 treatment. (No marked changes occurred in pulse rate or the electrocardiogram.) Wheatley [15] in 57 depressed patients from a General Practitioner Research group found that T3 (20-40 ug) potentiated the effects of amitriptyline (100 mg) within 10-14 days as compared with placebo. With the higher dose (40 ug), results were seen in three days in females. Responses were better in patients with thyroid function tests in the lower part of the normal range. In summary, antidepressant effects of T3 supplementation can occur with apparent euthyroid status, are not associated with significant side effects, and as Altshuler et al. [16] observed in a comprehensive review, the benefit of $\mathrm{T} 3$ to accelerate antidepressant response was significantly related to the percentage of women included in a study.

Refractory Depressed Patients, T3 Supplementation and Thyroid Function Tests (e.g., Case B below): In a study of refractory depressed patients (including postpartum women) unresponsive to tricyclic antidepressants, monoamine oxidase inhibitors (MAOIs) and up to 15 electroconvulsive treatments, who had normal TSH responses to TRH, the addition of 25 ug of T3 was associated with dramatic improvement in mood in 7-9 days [17]. A female patient with psychotic depression, who was unresponsive to antidepressant and antipsychotic treatment during a 1-year period of hospitalization, and who had normal baseline thyroid function tests but a blunted TSH response to TRH, started to respond to $5 \mathrm{ug}$ of T3 added to a MAOI (phenelzine 60 $\mathrm{mg}$ ) and antipsychotic (thiothixene $10 \mathrm{mg}$ ) regimen after 7 days, with full remission achieved over 5 weeks with T3 of $30 \mathrm{ug} /$ day [18].

In summary, even refractory depressed patients with normal baseline thyroid function tests responded to T3 supplementation of antidepressant medication in a relatively short period of time.

Treatment Response Rates in Relation to Thyroid Function (e.g., Case C below): In a double-blind randomized controlled trial of 20 patients with major depression and normal thyroid status, Souche et al [19]. found that clomipramine (150 mg/day) plus T3 (50 ug) had superior efficacy in achieving remission of depressive symptoms compared with clomipramine and placebo after 28 days. T3 was without effect on clomipramine plasma levels. Abraham et al. [20] in a study of 12 outpatients (eight females, four males) with non-psychotic major depression who failed to show satisfactory antidepressant response to an SSRI (citalopram, sertraline, fluvoxamine, paroxetine) after six weeks of treatment despite normal TSH and TRH stimulation tests, administered 2550 ug of T3 for at least three weeks. Forty-two percent showed a $\geq$ $50 \%$ improvement on interview-based assessments of depression [21]. Responders vs. nonresponses did not differ on baseline depression severity, previous antidepressant treatment, gender or change in TSH with TRH stimulation.

In 124 outpatients with major depressive disorder without psychotic features (DSM-IV criteria), Cooper-Kazaz et al. [22] in a randomized, double-blind placebo-controlled trial of sertraline hydrochloride (up to $100 \mathrm{mg} /$ day) plus liothyronine sodium (up to $50 \mu \mathrm{g} /$ day) vs. sertraline plus placebo, found that response rate ( $\geq 50 \%$ decrease on 21 -item HDRS) was $70 \%$ and $50 \%$ in the sertraline-liothyronine and sertraline-placebo groups, respectively, and remission rates (HDRS $\leq 6$ ) were $58 \%$ with sertraline-liothyronine and $38 \%$ with sertraline-placebo. In patients treated with liothyronine-sertraline, remission was associated with lower baseline T3 values and after treatment, with a decrease in serum thyrotropin values. 
In summary, these studies underscore the observation that treatment response to $\mathrm{T} 3$ is not predicted by abnormalities in thyroid function tests.

T3 Study Response Rates: As reviewed by Joffe et al. [23] investigators conducting open studies examining T3 augmentation of antidepressant treatments reported response rates of 25$90 \%$, with a majority reporting response rates in excess of $65 \%$. In controlled studies, authors generally reported response rates in the range of $50-65 \%$. Responses were more limited in other studies: Thase et al. [24] found that among 20 (7 male, 13 female) outpatient unipolar depressives unresponsive to $\geq 12$ weeks of treatment with imipramine (mean dose $240 \mathrm{mg}$ /day) plus interpersonal psychotherapy, only $25 \%$ of patients responded to the addition of $25 \mathrm{ug}$ of T3 after another 4 weeks. Targum et al. [25] found a $33 \%(7 / 21)$ response rate to thyroid supplementation and Gitlin et al. [26] found no benefit of T3 augmentation compared with placebo in a double-blind cross-over trial of 16 imipramineresistant outpatients. The inpatient study of Birkenhager et al. [27] also found no efficacy of four weeks of T3 augmentation (37.5 ug) in 14 severely depressed melancholic and/or psychotic patients unresponsive to nortriptyline after six weeks. In many of these studies, with both positive and negative findings, the sample sizes were too small, and therefore under-powered, to demonstrate statistical significance.

Long-term Benefits and Risks: In a long-term augmentation study of T3 in refractory major depression, Kelly and Lieberman [28] found that 14 of 17 patients showed improvement on T3 over 24.2 months with an average dose of 80 ug (range 25-150ug). All females responded. All patients who stopped T3 augmentation because of side effects (leg tremor, sluggishness, irritability, anxiety) or failure to respond were male (43\% of males). No patients developed osteopenia, osteoporosis, atrial fibrillation or other major adverse advents. In most patients $(10 / 14,71 \%)$, the initial positive response was lost, but upward readjustment of the T3 dose re-established full and sustained benefits. Ricken et al. [29] also noted no long-term treatment effects on bone mineral density with supraphysiological doses of thyroid hormone used in treating mood disorder patients. Age, thyroxine dose or postmenopausal status did not predict a decline in bone mineral density.

In summary, long term treatments with $\mathrm{T} 3$ do not pose a significant risk for the development of adverse physiological effects. As reviewed by Kelly [30] high dose thyroid was not a significant risk factor for osteoporosis, while untreated depressions did pose a risk.

A Multi-center Staged Trial: In the Sequenced Treatment Alternatives to Relieve Depression (STAR*D) study, [31] a large multicenter trial of primary and specialty care clinic outpatients ( $n=4,041)$ with nonpsychotic major depressive disorder, patients who did not respond to Level 1 initial treatment with a selective serotonin reuptake inhibitor (SSRI) antidepressant medication, i.e., citalopram or Level 2 switched treatments (e.g., sustained release bupropion, sertraline, extended-release venlafaxine or cognitive therapy), were offered Level 3 random assignment for 14 weeks to either a medication switch (i.e., nortriptyline or mirtazapine) or augmentation of their current antidepressant with lithium (up to $900 \mathrm{mg} /$ day) or T3 (25-50 $\mu \mathrm{g} /$ day). In comparing lithium vs. T3 augmentation in patients who had failed two medication trials for depression, [32] remission rates (a score of $\leq 7$ on the 17-item Hamilton Depression Rating Scale) were $24.7 \%$ with T3 augmentation and $15.9 \%$ with lithium augmentation. Although the difference between treatments was not statistically significant, lithium was more frequently associated with side effects and with participants leaving treatment due to side effects. The authors concluded that the lower side effect burden and ease of use of T3 augmentation suggested that it had advantages over lithium augmentation for depressed patients unresponsive to medication trials.

Meta-analyses: The use of T3 as an augmentation strategy for the treatment of refractory depression also is supported by the recent meta-analyses of Chang and Zhou [33,34]. Although these studies focused on the role of T3 as an augmenting agent in treatment-resistant unipolar depression, $\mathrm{T} 4$ has been used in the treatment of a severe form of bipolar illness, characterized by rapid cycles of mood (see below). In emerging treatment paradigms for thyroid hormone replacement therapies for hypothyroidism, combination therapy with T4 plus T3 now is recommended more frequently [35].

\section{Rapid-Cycling Bipolar Illness}

Rapid cycling bipolar illness, defined as four or more episodes of mania and depression per year [37], predominates in women. In addition to be a woman, two other factors have been associated with the rapid cycling form of bipolar illness: (1) treatment with tricyclic antidepressants, and (2) hypothyroidism. Women, compared with men, show an increased incidence of both druginduced rapid cycling and hypothyroidism. Thus, women's increased risk for hypothyroidism may put them at increased risk for rapid-cycling bipolar illness that together may provide further treatment challenges [38,39] Studies that document sex differences indicate that almost all patients who are treated for bipolar illness with lithium, who then develop hypothyroidism, are female. In studies by Villeneuve et al., Transbol et al. and Cho et al., [40,41,42] 90 to 100 percent of bipolar patients with lithiuminduced hypothyroidism were women. In a review by Fyro et al., [43] 14 of 22 reported cases in which hypothyroidism developed during lithium treatment, all but one was women.

Reproductive status also may affect the appearance of thyroid disease and rapid cycling. There is a common appearance of goiter during puberty, pregnancy, and menopause [39]. Induction of rapid cycles of mood may occur in the postpartum period when 
women particularly are prone to develop hypothyroidism $[44,45]$. This type of hypothyroidism may represent an autoimmune phenomenon, as the extent of postpartum hypothyroidism correlates with levels of microsomal antibodies early in pregnancy [46]. Gonadal steroids are required to maintain, and may enhance, the normal TSH response to TRH in the female, but not the male $[47,48]$. Estrogen may induce rapid cycling or at least predispose to tricyclic-induced rapid cycling as reported by Oppenheim [49]. Progesterone, on the other hand, may suppress rapid cycles of $\operatorname{mood}[50]$.

In summary, cyclic mood disorders in the form of rapid cycling manic-depressive illness are more prevalent in women. Treatment with antidepressant drugs often precipitates rapid mood cycles, particularly in women with bipolar II illness. Thyroid impairment, more prevalent in women, also is associated with the rapid cycling form of the illness. Although women are uniquely vulnerable to thyroid impairment, depressed women appear to be uniquely responsive to treatment with thyroid hormone [9,51]. Thus, reproductive hormones may alter the course of affective illness via their interaction with thyroid hormones and antidepressant drugs.

\section{Hypermetabolic Thyroid Treatment of Rapid Cycling Mood Disorders}

Thyroid hormone has been used to treat both cyclical and noncyclical forms of mood disorders. Hypermetabolic thyroid treatment (i.e., thyroxine 44 mgrm or intramuscular doses of initially 2 mgrm increased over 10 days to 40-50 mgrm) first was used by Gjessing in the 1930s to treat periodic catatonia and rapid cycling mood disorders [52]. Stancer and Persad [51] reported treatment of intractable rapid cycling bipolar illness with levothyroxine up to $0.5 \mathrm{mg}$ daily in euthyroid patients whose onset of illness was during the postpartum or involutional period, and who previously required long-term or frequent hospitalizations. Five of the seven women responded to hypermetabolic doses of thyroid hormone. The effect of thyroid hormone had differential effects in men and women. The treatment was unsuccessful in two men and one adolescent girl, who was treated with liothyronine instead.

In an uncontrolled and controversial study, women with rapid cycles of mood linked to the menstrual cycle (premenstrual syndrome) were reported to have a high incidence of thyroid disease (increased TSH response to TRH and anti-thyroid antibodies), and thyroid supplementation (levothyroxine 0.15 $\mathrm{mg}$ ) was found to improve their cyclic mood symptoms [53]. T4 also has been used for bipolar depressions without rapid cycling: Baumgartner observed marked beneficial effects of thyroxine (250-500 ug/day) in six patients with intractable non-rapid cycling bipolar disorder when used in combination with antidepressant or neuroleptic medication [54]. In summary, treatment with T4 has been found to help stabilize particularly rapid-cycling mood disorders.

\section{Proposed Mechanisms of Thyroid Hormone Effects on Mood}

As reviewed by Bauer et al.,[55] the potential mechanisms by which thyroid hormones may affect mood include interactions between thyroid hormones and neurotransmitters such as norepinephrine, dopamine and serotonin by a reduction in the sensitivity of auto receptors or an increase in receptor sensitivity affecting post-receptor and signal transducing processes, or by affecting gene regulatory mechanisms, deiodinase activity and nuclear binding to genetic loci, thereby altering protein synthesis. The mechanisms for thyroid-enhancement of responses to antidepressants may be as Whybrow and Prange suggest[56] related to the capacity of thyroid hormone to alter the ratio of alpha to beta adrenergic receptors and their sensitivity to noradrenergic neurotransmitters. Jackson [57] suggested an impairment in the inhibitory glucocorticoid feedback pathway from the hippocampus to the hypothalamus. Bunevicius et al.[58] propose an autoimmune thyroid process may be related to mood and anxiety disorders, as they found in a primary health care setting that patients with hypo-echoic thyroid $(n=122)$ were primarily women and were older compared with normo-echoic thyroid.

Women, but not men, with hypo-echoic thyroid had higher scores on anxiety scales, and among women with hypo-echoic thyroid, premenopausal, but not postmenopausal, women had a greater prevalence of higher depressive symptom scores and were more likely to be using psychiatric medications. As D R Thomas [59] pointed out, reduced conversion of T4 to T3 may be a means of conserving energy in depression, often characterized by weight loss. This theory, however, was not substantiated in a study of $\mathrm{T} 3$ and T4 in a group of unipolar depressed patients and healthy comparison subjects [60]. A particularly specific model of thyroid involvement in depression is suggested by seasonal regulation of endocrine systems in mammals, birds, and lower animals [61-64]. Such seasonal regulation is mediated largely by the photoperiod, which is the seasonally varying duration of daylight within the 24 hours. Long photoperiods produce summer responses, and short photoperiods produce winter responses.

Since some patients with recurrent depression have a seasonal mood pattern, with winter depression being the best studied manifestation, and winter depression responds to bright light treatment, winter depression is thought to be homologous to mammalian winter loss of fertility [34]. Moreover, it recently has been demonstrated that patients with unipolar depressions that are not seasonal also respond well to bright light treatment, perhaps somewhat better than to fluoxetine, although the combination may be better than either treatment alone. ${ }^{65}$ Photoperiodic regulation of the endocrine system is mediated through light suppression and curtailment of pineal secretion of melatonin, a night hormone, causing nocturnal melatonin secretion to be abbreviated in summer as compared with winter, as if melatonin were a marker of darkness [65]. In the long nights 
of winter, melatonin acts on thyrotropic cells in the pars tuberalis of the pituitary to suppress TSH synthesis and secretion. An elegant genetic transcription mechanism has been described by which melatonin regulates expression of the transcription factor EYA3 that along with TEF (thyrotropin endocrine factor) regulates transcription of the TSHB protein.

Pars tuberalis TSH passes retrograde through the third cerebral ventricle to ependymal lining cells, where TSH promotes transcription of deiodinase 2 that converts T4 hormone to T3. In the hypothalamus, T3 then regulates the gonadotropic reproductive hormones and indirectly, the pituitary hormones. Other pars tuberalis tuberalin polypeptides also regulate the pituitary. Thus, induction of depression because of insufficient light exposure could be mediated by hypothalamic T3. Another little-understood effect is that of pars tuberalis TSH that passes into the blood stream, where it is ineffective in promoting thyroid synthesis of thyroid hormones, due to an odd form of TSH glycosylation produced by pars tuberalis [66]. There is littleunderstood evidence that the glycosylation and sialylation state of blood TSH is a factor in the antidepressant response to sleep deprivation [67]. Moreover, a variety of polymorphisms in genes regulating thyroid metabolism seem to be associated with mood disorders [64].

Problems in finding more distinct relationships between depressive disorders and blood T3 may arise from the importance of the T3 specifically localized in the hypothalamus, which is regulated by pars tuberalis. Hypothalamic T3 is little regulated by peripheral TSH. Blood T4 passes poorly into the brain though T4 concentrations have some influence on hypothalamic synthesis of T3 (from T4). Most of the T3 in the brain is synthesized within the brain. Blood thyroid function assessments simply do not reflect much of what is happening in pars tuberalis and the hypothalamus. Yet, we have no means of assaying hypothalamic T3 in living humans. Also, perhaps the functional hypothyroidism related to depression would be clarified if more attention were given to the glycosylation and sialylation states of circulating TSH. We do not understand any gender differences in photoperiodic regulation of hypothalamic T3, though it is well established that winter depression is most common among premenopausal women, and photoperiod regulates estrous cycles among laboratory rodents.

In summary, depressed women responsive to thyroid (T3) augmentation of antidepressant medication may be responding most specifically to hypothalamic T3.

\section{Case Reports}

Ms. A was a 26-year-old nursing student, with a personal and family history of depression, previously unresponsive to $20 \mathrm{mg}$ fluoxetine. She presented with symptoms of an atypical depression with hypersomnia, hyperphagia, lethargy, difficulty concentrating and loss of energy. It was a major effort to get up in the morning, shower and dress. Particularly disturbing to her was her anhedonia and lack of motivation in carrying out her previous active lifestyle. She described herself when not depressed as a very energetic, outgoing person, "who loved life, her family, sports and hiking." Her symptoms exacerbated with the loss of her father the previous year and during the winter months, but symptoms were not particularly responsive to light therapy, which gave her headaches. Increased doses of fluoxetine had caused problematic side effects of dizziness and headache, requiring a reduction in dose. Other SSRIs (i.e., sertraline) had caused gastrointestinal side effects.

She was placed on bupropion XL $150 \mathrm{mg}$ which partially helped her depressive symptoms but could not be increased because of the side effect of excess agitation ("like I had too much coffee to drink"). She was euthyroid. She was prescribed 25 ug of T3, reported a "remarkable" change within two weeks, and asked to be increased to $50 \mathrm{ug}$ after a month. While she had been struggling to stay motivated to continue her studies, she now felt "energized" to pursue these studies in addition to her previous active lifestyle, engaging in family and community activities. At the recommendation of her primary care physician, she returned to $25 \mathrm{ug}$, but had a relapse of her depressive symptoms. For maintenance treatment, she was placed on 37.5 ug of T3, which she did not consider optimal for her, but enough to continue her studies and assist other family members, including her siblings, in coping with the loss of their beloved father.

Mrs. B was a 48-year-old female with a history of recurrent major depression unable to tolerate other than very low doses of SSRIs due to her sensitivity to development of serotonin syndromes. With the onset of irregular menses during the perimenopause, she developed what traditionally was described as "involutional melancholia" with psychomotor retardation in activity and speech, somatic symptoms, diurnal variation of mood with early morning awakening and "an abiding sense of tragedy" without significant vasomotor symptoms. This state made it very difficult to care for her two teenage autistic sons. Low dose desipramine (25 mg) was helpful in relieving her core depressive symptoms, but a sense of hopelessness and helplessness remained. Her free T4 levels were low 0.25 (0.89-1.76 ng/dL normal range) and TSH and T3 were within normal limits. She was not a candidate for estrogen replacement therapy to augment her antidepressant medication because of a seizure that had occurred previously. She was placed on 25 ug of T3. Within a week, her therapist observed marked mood elevation, increased energy and decreased poverty of speech. Her dose was reduced to 12.5 ug given her sensitivity to side effects of medications. She has remained on that dose for the last 9 months without recurrence of depressive symptoms.

Mrs. C was a 49-year-old attorney with a family history of depressive illness, who was prescribed duloxetine increased to 60 $\mathrm{mg} /$ day for the development of a new onset of perimenopausal depression without significant vasomotor symptoms. Selective serotonin-norepinephrine reuptake inhibitors-SNRIs and tricyclic antidepressants work better than selective serotonin reuptake inhibitors-SSRIs for the treatment of perimenopausal 
depression in women who are not receiving estrogen replacement therapy [68]. Although duloxetine helped improve her ability to cope with stresses at work and in family life (particularly the adolescent step-children of her second husband), she was still left with many anergic and anhedonic symptoms feeling (as her therapist summarized), like Hamlet, “...How weary, stale, flat and unprofitable seem to me all the uses of this world..." (Hamlet, 1.2.137-138) [69]. Despite her euthyroid status, within three weeks of the addition of $\mathrm{T} 3$, she reported feeling much more "bright-eyed and bushy-tailed", eager to take on the challenges of work and home life without feeling overwhelmed by them. I "feel back to my normal self" she reported. She has remained well for the last six months and has not felt the need to increase the dose of her medication.

\section{Treatment Guidelines}

\section{Treatment-Resistant Unipolar Depression}

For women with refractory depression, it behooves the clinician to follow the guidelines from a STAR*D report, as it reflects the findings from a rigorous multi-site study of 4,041 patients: If a patient, particularly a woman, has not responded to initial treatment with an SSRI (Level 1), bupropion, SNRI or cognitive behavior therapy (Level 2), then augmentation with T3 (25-50 ug/day) for 14 weeks (Level 3) would be supported by ample clinical research. (Note, other Level 3 treatments include switching to a tricyclic antidepressant or lithium, but these medications, although potentially efficacious, may have more problematic side effects.) Benefit may be observed within one to two weeks in some patients. Side effects include agitation, anxiety, irritability, headache, tachycardia, tremor, diaphoresis, nausea and diarrhea, some of which may diminish over the first two weeks of treatment. Potential long-term effects may include menstrual irregularities, osteopenia and osteoporosis, although no decreases in bone mineral density have been observed in studies up to 2 years.

Levels of TSH, free T4 and T3 should be checked at baseline, and once a stable dose is reached, every six months thereafter. Dosage adjustment should be guided by clinical symptoms and side effects more than blood levels. Overt hypothyroidism in a pregnant or postpartum woman should be treated. T3 treatment in pregnancy is Risk Category A (adequate, well-controlled studies in pregnant women have failed to demonstrate risk to the fetus). Thyroid hormones do not cross the placental barrier readily, and clinical experience to date does not indicate any adverse effect on fetuses when thyroid hormones are administered to pregnant women, but studies investigating thyroid supplement to antidepressant and mood-stabilizing medication have not included pregnant or lactating women. Although some T3 is found in mother's breast milk, no known adverse effects have been reported. Thus, caution is advised: the clinician must weigh the benefits of treating depression, which are substantial, and risks of breast-feeding versus non-treatment to both the infant and the mother.

\section{Rapid-Cycling Mood Disorders}

As the studies reviewed above examining the effects of hypermetabolic doses of T4 in rapid-cycling mood disorders have occurred primarily on inpatient psychiatric units, referral to these specialists for monitoring is warranted. Generally, doses of 150200 ug of T4 enough to suppress TSH are required to stabilize rapid cycles of mood over the course of several weeks. Side effects, in addition to those described above for T3, may include palpitations, atrial fibrillation, insomnia, and longer term, increased appetite, weight loss, heat intolerance and congestive heart failure. Thyroid hormone supplementation should not be used if the patient has uncorrected adrenal cortical insufficiency, and dosages may need to be adjusted in patients on oral anticoagulants, insulin, oral hypoglycemics or digitalis. Also, 4-5 hours should elapse between the ingestion of cholestyramine and thyroid hormones.

\section{Conclusion}

As the studies, case reports and treatment guidelines described above explain, for treatment-resistant depression, a valuable therapeutic strategy may be T3 augmentation of 25-50 ug daily added to antidepressant medication over the course of 14 weeks to determine efficacy, with benefit often obtained within 1-2 weeks and with relatively minor side effects compared with other treatment alternatives. Responses usually are better among women than among men. T3 alone generally is not enough in alleviating depressive symptoms. Abnormal thyroid indices are not a prerequisite for treatment benefit. Response rates vary from 50-65\% in most controlled studies, but some studies report either lower or higher rates of response. The use of T3 for antidepressant treatment for unipolar depressions is well-substantiated. In contrast, the work describing hypermetabolic doses of T4 is more research-based, and when used generally in the range of 150-200 ug enough to suppress TSH, is designed for women with rapidcycling mood disorders.

This intervention initially should be implemented on inpatient psychiatric units where thyroid function and mood can be monitored closely. Although some clinicians are concerned about long-term effects on the brain or end organs, studies to date do not suggest adverse effects of relatively long-term use when thyroid hormone treatments are indicated for depression. Dosages of other medications (e.g., oral contraceptives, hormone replacement therapy, carbamazepine) may need to be adjusted to avoid potential drug interactions. Caution is advised when thyroid supplementation is administered in pregnant or lactating women. The potential side effects of thyroid augmentation must be weighed against the potential side effects of an untreated depression that include adverse medical and psychosocial effects 
on the individual and family, the workplace and society. The risks of augmenting depression treatment with thyroid hormones are far less than the risks of an inadequately treated depression that potentially may lead to increased severity, frequency and more treatment-resistant depressive episodes.

Further research is needed to clarify appropriate dosages of T3 and T4, the best antidepressants to combine with them, the desirable time course of treatment, and any long-term benefits or risks. For augmentation of antidepressant treatments, the relative merits of $\mathrm{T} 3$, bright light treatments and their combination need study. To understand depression treatments better, more basic research is needed on the roles of local hypothalamic thyroid metabolism and sialylation of blood TSH.

\section{References}

1. Parry BL (1995) Mood Disorders Linked to the Reproductive Cycle in Women. In: Bloom FE, Kupfer DJ (eds.) Psychopharmacology: The Fourth Generation of Progress. Raven Press Ltd, New York, USA, Pp: 1029-1042.

2. Pearce EN (2007) Thyroid dysfunction in perimenopausal and postmenopausal women. Menopause Int 13(1): 8-13.

3. Premachandra BN, Kabir MA, Williams IK (2006) Low T3 syndrome in psychiatric depression. J Endocrinol Invest 29(6): 568-572.

4. Abulseoud O, Sane N, Cozzolino A, Kiriakos L, Mehra V , et al. (2007) Free T4 index and clinical outcome in patients with depression. J Affect Disord 100(1-3): 271-277.

5. Joffe RT, Singer W (1990) A comparison of triiodothyronine and thyroxine in the potentiation of tricyclic antidepressants. Psychiatry Res 32(3): 241-251.

6. Feldmesser Reiss EE (1958) The application of triiodothyronine in the treatment of mental disorders. J Nerv Ment Dis 127(6): 540-545.

7. Flach FF, Celian CI, Rawson RW (1958) Treatment of psychiatric disorders with triiodothyronine. Am J Psychiatry 114(9): 841-842.

8. Wilson IC, Prange AJ, Lara PP (1974) L-triiodothyronine alone and with imipramine in the treatment of depressed women. In: Prange AJ (ed) The Thyroid Axis, Drugs, and Behavior. Raven Press, New York, USA P: 49.

9. Prange AJ Jr, Wilson IC, Rabon AM, Lipton MA (1969) Enhancement of imipramine antidepressant activity by thyroid hormone. Am J Psychiatry 126: 457-469.

10. Prange AJ Jr, Wilson IC, Knox A, McClane TK, Lipton MA (1970) Enhancement of imipramine by thyroid stimulating hormone: clinical and theoretical implications. Am J Psychiatry 127: 191-199.

11. Goodwin FK, Prange AJ Jr, Post RM, Muscettola G, Lipton MA (1982) Potentiation of antidepressant effects by L-triiodothyronine in tricyclic nonresponders. Am J Psychiatry 139(1): 34-38.

12. Coppen A, Whybrow PC, Noguera R, Maggs R, Prange AJ Jr (1972) The comparative antidepressant value of L-tryptophan and imipramine with and without attempted potentiation by liothyronine. Arch Gen Psychiatry 26(3): 234-241.

13. Agid O, Lerer B (2003) Algorithm-based treatment of major depression in an outpatient clinic: clinical correlates of response to a specific serotonin reuptake inhibitor and to triiodothyronine augmentation Int J Neuropsychopharmacol 6(1): 41-49.
14. Tsutsui S, Yamazaki Y, Namba T, Tsushima M (1979) Combined therapy of T3, and antidepressants in depression. J Int Med Res 7(2): 138-146.

15. Wheatley D (1972) Potentiation of amitriptyline by thyroid hormone. Arch Gen Psychiatry 26(3): 229-233.

16 Altshuler LL, Bauer M, Frye MA, Gitlin MJ, Mintz J, et al. (2001) Does thyroid supplementation accelerate tricyclic antidepressant response? A review and meta-analysis of the literature. Am J Psychiatry 158(10): 1617-1622.

17. Extein I (1982) Case reports of L-triiodothyronine potentiation. Am J Psychiatry 139(7): 966-967.

18. Hullett FJ, Bidder TG (1983) Phenelzine plus triiodothyronine combination in a case of refractory depression. J Nerv Ment Dis 171(5): 318-320.

19. Souche A, Baumann P, Koeb L, Thermoz P, Azorin JM, et al. (1991) Treatment of depression by a combination of clomipramine and triiodothyronine. Encephale 17(1):37-42.

20. Abraham G, Milev R, Stuart Lawson J (2006) T3 augmentation of SSRI resistant depression. J Affect Disord 91(2-3): 211-215.

21. Hamilton M (1960) A rating scale for depression. J Neurol Neurosurg Psychiatry 23: 56-62.

22. Cooper Kazaz R, Apter JT, Cohen R, Karagichev L, Muhammed-Moussa $S$, et al. (2007) Combined treatment with sertraline and liothyronine in major depression: a randomized, double-blind, placebo-controlled trial. Arch Gen Psychiatry 64(6): 679-688.

23. Joffe RT, Sokolov ST, Singer W (1995) Thyroid hormone treatment of depression. Thyroid 5: 235-239.

24. Thase ME, Kupfer DJ, Jarrett DB (1989) Treatment of imipramineresistant recurrent depression: I. An open clinical trial of adjunctive L-triiodothyronine. J Clin Psychiatry 50(10): 385-388.

25. Targum SD, Greenberg RD, Harmon RL, Kessler K, Salerian AJ, et al. (1984) Thyroid hormone and the TRH stimulation test in refractory depression. J Clin Psychiatry 45: 345-346.

26. Gitlin MJ, Weiner H, Fairbanks L, Hershman JM, Friedfeld N (1987) Failure of T3 to potentiate tricyclic antidepressant response. J Affect Disord 13(3): 267-272.

27. Birkenhager TK, Vegt M, Nolen WA (1997) An open study of triiodothyronine augmentation of tricyclic antidepressants in inpatients with refractory depression. Pharmacopsychiatry 30(1): 2326.

28. Kelly TF, Lieberman DZ (2009) Long term augmentation with T3 in refractory major depression. J Affect Disord 115(1-2): 230-233.

29. Ricken R, Bermpohl F, Schlattmann P, Bschor T, Adli M, et al. (2012) Long-term treatment with supraphysiological doses of thyroid hormone in affective disorders - effects on bone mineral density. J Affect Disord 136(1-2): e89-94.

30. Kelly T (2014) A favorable risk-benefit analysis of high dose thyroid for treatment of bipolar disorders with regard to osteoporosis. J Affect Disord 166: 353-358

31. Rush AJ, Fava M, Wisniewski SR, Lavori PW, Trivedi MH, et al. (2004) Sequenced treatment alternatives to relieve depression (STAR*D): rationale and design. Control Clin Trials 25(1): 119-142.

32. Nierenberg AA, Fava M, Trivedi MH, Wisniewski SR, Thase ME, et al. (2006) A comparison of lithium and T(3) augmentation following two failed medication treatments for depression: a STAR*D report. Am J Psychiatry 163(9): 1519-1530. 
33. Chang CM, Sato S, Han C (2013) Evidence for the benefits of nonantipsychotic pharmacological augmentation in the treatment of depression. CNS Drugs 27: S21-27.

34. Zhou X, Ravindran AV, Qin B, Del Giovane C, Li Q et al. (2015) Comparative efficacy, acceptability, and tolerability of augmentation agents in treatment-resistant depression: systematic review and network meta-analysis. J Clin Psychiatry 76(4): e487-498.

35. Wiersinga WM (2014) Paradigm shifts in thyroid hormone replacement therapies for hypothyroidism. Nat Rev Endocrinol 10(3): 164-174.

36. Dunner DL, Patrick V, Fieve RR (1977) Rapid cycling manic depressive patients. Compr Psychiatry $18: 561-566$.

37. Wehr TA, Sack DA, Rosenthal NE, Cowdry RW (1988) Rapid cycling affective disorder: contributing factors and treatment responses in 51 patients. Am J Psychiatry 145(2): 179-184.

38. Cowdry RW, Wehr TA, Zis AP, Goodwin FK (1983) Thyroid abnormalities associated with rapid-cycling bipolar illness. Arch Gen Psychiatry 40(4): 414-420.

39. Ingbar SH, Woeber KA (1981) The Thyroid Gland. In: Williams RH (ed.) Textbook of Endocrinology. ( $6^{\text {th }}$ edn.) WB Saunders, Philadelphia, USA, Pp: 117-247.

40. Villeneuve A, Gautier J, Jus A, Perron D (1974) The effect of lithium on thyroid in man. Int J Clin Pharmacol 9: 75-80.

41. Transbol I, Christiansen C, Baastrup PC (1978) Endocrine effects of lithium. I. Hypothyroidism, its prevalence in long-term treated patients. Acta Endocrinol (Copenh) 87(4): 759-767.

42. Cho JT, Bone S, Dunner DL, Colt E, Fieve RR (1979) The effect of lithium treatment on thyroid function in patients with primary affective disorder. Am J Psychiatry 136(1): 115-116.

43. Fyro B, Petterson U, Sedvall G (1973) Time course for the effect of lithium on thyroid function in men and women. Acta Psychiatr Scand 49(3): 230-236.

44. Herzog A Detre T (1974) Postpartum psychoses. Dis Nerv Syst 35: 556559.

45. Jansson R, Bernander S, Karlsson A, Levin K, Nilsson G (1984) Autoimmune thyroid dysfunction in the postpartum period. J Clin Endocrinol Metab 58: 681-687.

46. Amino N, Mori H, Iwatani Y, Tanizawa O, Kawashima M, et al. (1982) High prevalence of transient post-partum thyrotoxicosis and hypothyroidism. N Engl J Med 306(14): 849-852.

47. Ramey JN, Burrow GN, Polackwich RJ, Donabedian RK (1975) The effect of oral contraceptive steroids on the response of thyroid-stimulating hormone to thyrotropin-releasing hormone. J Clin Endocrinol Metab 40(4): 712-714.

48. Spitz IM, Zylber-Haran EA, Trestian S (1983) The thyrotropin (TSH) profile in isolated gonadotropin deficiency: a model to evaluate the effect of sex steroids on TSH secretion. J Clin Endocrinol Metab 57(2): 415-420.

49. Oppenheim G (1984) A case of rapid mood cycling with estrogen: implications for therapy. J Clin Psychiatry 45 :34-35.

50. Hatotani N, Nomura J (1983) Neurobiology of periodic psychoses. Tokyo: Igaku-Shoin.

51. Stancer HC, Persad E (1982) Treatment of intractable rapid-cycling manic-depressive disorder with levothyroxine. Clinical observations. Arch Gen Psychiatry 39(3): 311-312.

52. Gjessing R (1938) Disturbances of somatic functions in catatonia with a periodic course, and their compensation. J Ment Sci 84: 608.

53. Baumgartner A, Bauer M, Hellweg R (1994) Treatment of intractable non-rapid cycling bipolar affective disorder with high-dose thyroxine: an open clinical trial. Neuropsychopharmacology 10: 183-189.

54. Brayshaw ND, Brayshaw DD (1987) Premenstrual syndrome and thyroid dysfunction. Integr Psychiatry 5: 179-193.

55. Bauer M, Goetz T, Glenn T, Whybrow PC (2008) The thyroid-brain interaction in thyroid disorders and mood disorders. J Neuroendocrinol 20(10): 1101-1114.

56. Whybrow PC, Prange AJ (1981) A hypothesis of thyroid-catecholaminereceptor interaction. Its relevance to affective illness. Arch Gen Psychiatry 38(1): 106-113.

57. Jackson IM (1998) The thyroid axis and depression. Thyroid 8(10): 951-956.

58. Bunevicius R, Peceliuniene J, Mickuviene N, Bunevicius A, Pop VJ, et al. (2007) Mood and thyroid immunity assessed by ultrasonographic imaging in a primary health care. J Affect Disord 97: 85-90.

59. Thomas DR (1986) T3 and T4 in unipolar depression. Biol Psychiatry 21: 576-577.

60. Orsulak PJ, Crowley G, Schlesser MA, Giles D, Fairchild C, et al. (1985) Free triiodothyronine (T3) and thyroxine (T4) in a group of unipolar depressed patients and normal subjects. Biol Psychiatry 20: 10471054 .

61. Dardente H, Wyse CA, Birnie MJ, Dupré SM, Loudon AS, et al. (2010) A molecular switch for photoperiod responsiveness in mammals. Curr Biol 20(24): 2193-2198.

62. Masumoto KH, Ukai-Tadenuma M, Kasukawa T, Nagano M, Uno KD, et al (2010) Acute induction of Eya3 by late-night light stimulation triggers TSHbeta expression in photoperiodism. Curr Biol 20(24): 2199-2206.

63. Hazlerigg D (2012) The evolutionary physiology of photoperiodism in vertebrates. Prog Brain Res 199: 413-422.

64. Kripke DF, Elliott JA, Welsh DK, Youngstedt SD (2015) Photoperiodic and circadian bifurcation theories of depression and mania. F1000Res 4: 107.

65. Lam RW, Levitt AJ, Levitan RD, Michalak EE, Cheung AH, et al. (2016) Efficacy of Bright Light Treatment, Fluoxetine, and the Combination in Patients with Nonseasonal Major Depressive Disorder: A Randomized Clinical Trial. JAMA Psychiatry 73: 56-63.

66. Ikegami K, Liao XH, Hoshino Y, Ono H, Ota W, et al. (2014) Tissuespecific posttranslational modification allows functional targeting of thyrotropin. Cell Rep 9(3): 801-810.

67. Orth DN, Shelton RC, Nicholson WE, Beck-Peccoz P, Tomarken AJ, et al (2001) Serum thyrotropin concentrations and bioactivity during sleep deprivation in depression. Arch Gen Psychiatry 58: 77-83.

68. Sloan DM, Kornstein SG (2003) Gender differences in depression and response to antidepressant treatment. Psychiatr Clin North Am 26: 581-594.

69. Shakespeare W Hamlet, Prince of Denmark. In: Craig WJ (ed). The Complete Works of William Shakespeare. Oxford University Press, London, Pp. 1914.

70. Post RM (2007) Kindling and sensitization as models for affective episode recurrence, cyclicity, and tolerance phenomena. Neurosci Biobehav Rev 31(6): 858-873. 

$\begin{array}{ll}\text { (CC) } & \begin{array}{l}\text { This work is licensed under Creative } \\ \text { Commons Attribution 4.0 Licens } \\ \text { DOl: } 10.19080 / J E T R .2020 .05 .555663\end{array}\end{array}$
Your next submission with Juniper Publishers will reach you the below assets

- Quality Editorial service

- Swift Peer Review

- Reprints availability

- E-prints Service

- Manuscript Podcast for convenient understanding

- Global attainment for your research

- Manuscript accessibility in different formats

( Pdf, E-pub, Full Text, Audio)

- Unceasing customer service

Track the below URL for one-step submission https://juniperpublishers.com/online-submission.php 